\title{
BIOTECNOLOGIA DE CÉLULAS TRONCO MESENQUIMAIS: PRINCIPAIS APLICAÇÕES EM MEDICINA VETERINÁRIA E PERSPECTIVAS GERAIS
}

\author{
Elaine Cristina Galhardo ${ }^{1}$, Ariane Dantas ${ }^{1}$, Aline Sousa Camargos ${ }^{2}$, Fernanda da Cruz Landim \\ 'Universidade Estadual Paulista - UNESP, aculdade de Medicina Veterinária e Zootecnia - FMVZ/UNESP Botucatu. \\ ${ }^{2}$ Instituto Federal Goiano - IFG, campus Morrinhos, GO. E-mail: galhardo.elaine@gmail.com
}

\begin{abstract}
RESUMO
Células-Tronco mesenquimais (CTMs) são células isoladas de tecidos adultos com a capacidade de originar células idênticas ou se diferenciar em células de tecidos especializados. Estudos acerca do cultivo in vitro e aplicação in vivo das CTMs têm mostrado o amplo horizonte a ser explorado em tratamentos regenerativos e modulação de processos inflamatórios, além do melhoramento de técnicas de engenharia de tecidos e desenvolvimento de biomateriais. A medicina veterinária tem apresentado, em diversas espécies, satisfatórios resultados advindos do potencial regenerativo e atividade parácrina característicos das CTMs. Essa revisão teve por objetivo evidenciar, de forma breve, promissores resultados da aplicação experimental das CTMs em medicina veterinária, seu panorama biotecnológico atual, limitações e perspectivas de evolução.
\end{abstract}

Palavras-chave: biologia celular, medicina regenerativa, regeneração de tecidos

\section{MESENCHYMAL STEM CELLS BIOTECHNOLOGY: MAIN APPLICATIONS IN VETERINARY MEDICINE AND GENERAL OUTLOOK}

\begin{abstract}
Mesenchymal Stem Cells (MSCs) are isolated from adult tissues and presents ability to originate identical cells or differentiate into specific tissue cells. Studies about in vitro culture and in vivo application of MSCs have pointed the potential to be explored in regenerative treatments and modulation of inflammatory processes, as well as the improvement of tissue engineering techniques and the development of biomaterials. Veterinary Medicine has presented, in several species, satisfactory results coming from the regenerative potential and paracrine activity characteristic of the MSCs. This review aimed, briefly showing promising results of the experimental MSCs application in Veterinary Medicine, its current biotechnological overview and general prospects.
\end{abstract}

Keywords: cell biology, regenerative medicine, tissue regeneration

\section{INTRODUÇÃO}

As células tronco mesenquimais (CTMs) apresentam alta capacidade de renovação e diferenciação, além de baixa imunogenicidade. As CTMs são consideradas células-tronco adultas pois podem ser isoladas a partir de vários tecidos maduros, como músculo esquelético, derme, osso, polpa dental, tecido adiposo, medula óssea e sangue periférico (CHEN et al., 2008a; BYDLOWSKI et al., 2009).

A alta capacidade migratória das CTMs permite que, quando implantadas em um organismo, sejam sensíveis às citocinas liberadas nos processos de inflamação tecidual, quando se inicia a migração das CTMs para os sítios onde o tecido necessita ser reparado (UCCELLI et al., 
2006). Uma vez que as CTMs chegam ao tecido alvo, fatores parácrinos são secretados por estas células. Estes fatores estão envolvidos no recrutamento de macrófagos e células do endotélio que participam do processo de cicatrização, daí a ativa participação das CTMs nos processos regenerativos (CHEN et al., 2008b).

No processo de isolamento das CTMs em laboratório, alguns critérios precisam ser adotados para caracterizar as células em cultivo in vitro, como aderência ao plástico e formato fibroblastóide e expressão positiva ou negativa de marcadores imunofenotípicos, conforme estabelecido pela Sociedade Internacional de Terapia Celular (DOMINICI, 2006).

Para serem caracterizadas como CTMs, alguns marcadores chamados CD (Cluster differentiation), específicos para determinadas proteínas expressas ou não na membrana celular ou no meio intracelular das CTMs, devem ser investigados por técnicas de biologia molecular ou celular. Os marcadores que devem apresentar expressão são chamados positivos, e alguns deles são $C D 24$, CD44 e CD90, enquanto os principais negativos são CD45, CD34 e CD14. A expressão de MHC-II também deve ser verificada, pois este marcador é referente à proteína responsável pela ativação dos linfócitos T e B, atuantes na resposta imunológica do organismo (FAN et al., 2016). Como característica das CTMs, a expressão de MHC-II deve ser baixa ou nula, pois estas células apresentam baixa imunogenicidade, o que as torna viáveis para aplicações in vivo, inclusive em transplantes heterólogos.

Essa revisão teve por objetivo evidenciar, de forma breve, promissores resultados da aplicação experimental das CTMs em medicina veterinária, seu panorama biotecnológico atual e perspectivas de evolução, por meio de dados descritos em artigos científicos experimentais indexados nas principais bases de pesquisa mundiais como Science Direct e Pubmed.

\section{APLICAÇÕES EXPERIMENTAIS DAS CTMS EM MEDICINA VETERINÁRIA}

A investigação das CTMs em medicina veterinária tem apresentado resultados muito satisfatórios em diversas espécies animais. Os chamados efeitos parácrinos das CTMs consistem na capacidade de produzir citocinas que interferem no microambiente de um tecido (RATAJCZAK et al., 2006). Esses efeitos têm sido descritos em diversas aplicações experimentais, as quais apontam o potencial das CTMs em regenerar danos teciduais e moderar processos inflamatórios quando aplicadas in vivo.

Em aplicação experimental de CTMs isoladas a partir de medula óssea em transplante de fígado entre linhagens diferentes de ratos, foi reiterada a ação imunomoduladora destas células. $O$ processo de rejeição aguda esperado no organismo receptor ao órgão transplantado de outra linhagem genética foi significantemente atenuado, com diminuição da apoptose e enzimas hepáticas, além de moderação das citocinas envolvidas na resposta imunológica (YANG et al., 2016).

A ação moduladora da inflamação local e potencial regenerativo das CTMs também foram descritos na regeneração do endométrio de ratas (ZHAO et al., 2015), na restauração do sistema circulatório e coração em cães com isquemia (SILVA et al., 2005), tratamento de osteoartrite (BLACK et al., 2007; KRISTON-PÁL et al., 2017), lesões renais (LIM et al.,2016), e recuperação de tecido ósseo em lesão cranio-facial em cães (LIU et al., 2013).

Estudos a respeito do meio condicionado, meio de cultivo no qual as células se proliferaram in vitro e que contém suas microvesículas de sinalização celular, têm sido conduzidos com resultados semelhantes aos da aplicação das CTMs. Foi descrito, em meio condicionado de CTMs derivadas de tecido adiposo de cães, a estimulação regenerativa de células neuronais e endoteliais in vitro (AL DELFI et al., 2016), o que salienta a possibilidade de tratamento de sequelas neurológicas com a aplicação desta técnica, que permite aplicar o potencial parácrino das CTMs sem transplantar as células. 
Em ortopedia veterinária, estudos sobre aplicação das CTMs têm sido amplamente desenvolvidos em equinos, pois estes apresentam similaridade na funcionalidade de seu tendão flexor com o tendão de aquiles humano, e as lesões de tendão mais frequentes em cavalos atletas são, também, similares às encontradas em pessoas atletas (PATTERSON-KANE; RICH, 2014); dessa forma, os avanços no tratamento dessas ocorrências estão ligados em medicina veterinária e humana.

Diversos autores têm descrito resultados positivos do tratamento de lesão de tendão de equinos com aplicação de CTMs (SMITH et al., 2010; CROVACE et al., 2010). Equinos com lesão de tendão tratados com CTMs foram acompanhados durante 5 anos, período no qual observou-se a recuperação tecidual e nenhum efeito adverso da aplicação dessas células (FORTIER; SMITH, 2008). Em aplicação autóloga de CTMs oriundas de medula óssea de um pônei com lesão do tendão flexor digital superficial, foi descrita a diferenciação in vivo das CTMs em tenócitos (SMITH et al., 2010). A capacidade de produzir matriz extracelular de cartilagem foi demonstrada in vitro em análise ultraestrutural de CTMs diferenciadas na linhagem condrogênica (LUESMA et al., 2016), onde a produção e secreção de material granular e a organização das fibras colágenas no microambiente foram observadas (Fig. 1).

Figura 1. Ultraestrutura de CTM diferenciada na linhagem condrogênica produzindo matriz extracelular cartilaginosa $(m)$. A- Vesículas de material granular $(m)$ concentradas próximas a membrana celular. B- Matriz granular secretada pela CTM no meio extra e intracelular (m). CFibras de colágeno com aspecto fibrilar. Adaptado de LUESMA et al., 2016.

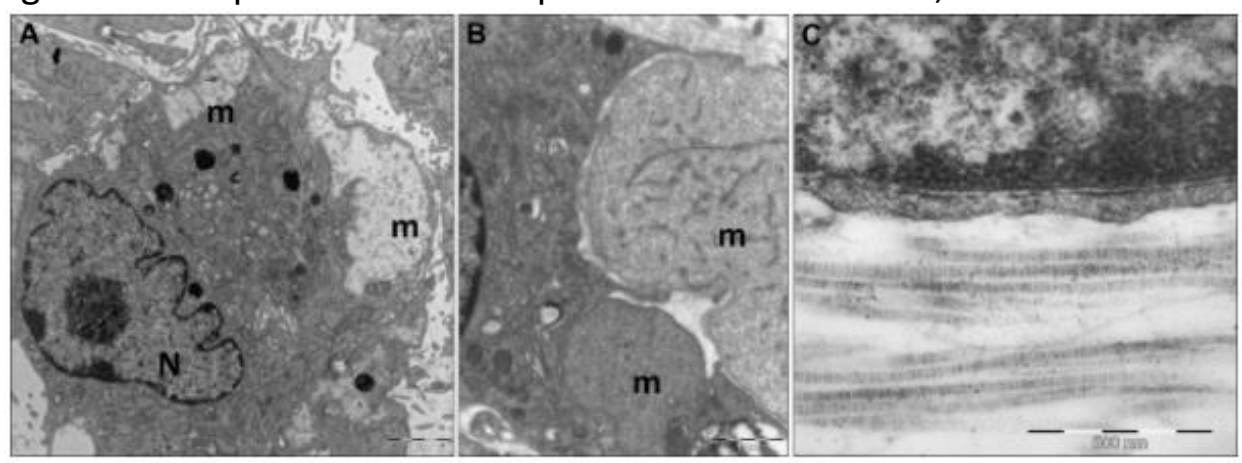

\section{PERSPECTIVAS GERAIS}

Além de ser o ponto chave da terapia regenerativa, o cultivo de CTMs in vitro é de grande valor na construção de técnicas otimizadas para a engenharia de tecidos, onde a interação das células com diferentes biomaterias pode ser testada. Estes testes propiciam condições de desenvolvimento de novas técnicas e aplicação segura de biomateriais e implantes in vivo.

Para realização de estudos de interação das CTMs com biomateriais, geralmente as CTMs são isoladas do tecido, cultivadas in vitro e postas em contato com o biomaterial a ser estudado, como quitosana (MOREAU e XU, 2009; RAGETLY et al., 2010), titânio (OLIVARES-NAVARRETE et al., 2010) ou ainda, nanomateriais baseados em carbono (KANG et al., 2017). Sendo um material biocompatível, a cultura de CTMs irá recobrí-lo e a interação poderá ser estudada. Diversos estudos têm utilizado CTMs com o objetivo de promover avanços na otimização de biomateriais empregados em cardiologia (CHERAGHI et al., 2017), implantes ósseos (DAHL et al., 2014) e odontologia (WINNING et al., 2017).

As perspectivas de crescimento de estudos acerca das CTMs também abrangem a produção animal, onde as CTMs são apontadas como potenciais ferramentas na recuperação de glândula mamária de animais leiteiros acometidos por mastite (SHARMA; JEONG, 2013), e na regeneração uterina de éguas com endometrite pós inseminação (FERRIS et al., 2014). 
É importante ressaltar que o uso de soro fetal bovino, fonte protéica amplamente utilizada no cultivo celular in vitro, é um fator limitante na aplicação in vivo das células cultivadas, uma vez que pode ser carreador de agentes infecciosos da espécie bovina ou provocar reação imunológica no receptor (SUNDIN et al., 2007). É interessante que sejam adotadas alternativas ao seu uso, como meios específicos serum-free disponíveis no mercado, soro autólogo (ESLAMINEJAD et al., 2009) ou lisado de plaquetas (BIEBACK et al., 2009), no entanto, isso tornaria o processo de cultivo mais oneroso e demorado.

\section{CONSIDERAÇÕES FINAIS}

As CTMs são uma ferramenta fundamental para otimização dos tratamentos regenerativos, e podem representar a evolução dos atuais tratamentos cirurgicos, alopáticos e protéticos em diversas áreas médicas. É indiscutível a importância da aplicação de modelos animais nas pesquisas sobre CTMs, pois a partir destes, pode ser vislumbrada a possibilidade de aplicações também em medicina humana, com resultados benéficos e em alternativa aos tratamentos atuais para diversas doenças frequentes na população humana.

A baixa imunogenicidade das CTMs aponta para a possibilidade de transplantes heterólogos com baixos índices de rejeição imunológica nos organismos receptores. No entanto, é preciso considerar a evolução dos receptores em longo prazo, o que pode ser uma limitação nos modelos experimentais animais devido ao curto tempo de vida dos mesmos em relação aos seres humanos. Sendo assim, estudos sobre esse importante tema devem ser estimulados e conduzidos com minúcia e responsabilidade, e as análises devem elucidar o comportamento das CTMs in vivo em longo prazo.

\section{REFERÊNCIAS}

AL DELFI, I.R.; SHEARD, J.J.; WOOD, C.R.; VERNALLIS, A.; INNES, J.F.; MYINT, P.; JOHNSON, W.E. Canine mesenchymal stem cells are neurotrophic and angiogenic: An in vitro assessment of their paracrine activity. The Veterinary Journal, v.217, p.10-17, 2016. https://doi.org/10.1016/j.tvjl.2016.09.003.

BIEBACK, K.; HECKER, A.; KOCAÖMER, A.; LANNERT, H.; SCHALLMOSER, K.; STRUNK, D.; KLÜTER, H. Human alternatives to fetal bovine serum for the expansion of mesenchymal stromal cells from bone marrow. Stem Cells, v.27, p.2331-2341, 2009. https://doi.org/10.1002/stem.139

BLACK, L.L.; GAYNOR, J.; GAHRING, D.; ADAMS, C.; ARON, D.; HARMAN, S.; GINGERICH, D.A.; HARMAN, R. Effect of Adipose-Derived Mesenchymal Stem and Regenerative Cells on Lameness in Dogs with Chronic Osteoarthritis of the Coxofemoral Joints: A Randomized, Double-Blinded, Multicenter, Controlled Trial. Veterinary Therapeutics, v.8, p.272-284, 2007.

CHEN, Y.; SHAO, J.Z.; XIANG, L.X.; DONG, X.J.; ZHANG, G.R. Mesenchymal stem cells: a promising candidate in regenerative medicine. The international journal of biochemistry \& cell biology, v.40, p.815-20, 2008a. https://doi.org/10.1016/i.biocel.2008.01.007.

CHEN, L.; TREDGET, E.E.; WU, P.Y.G.; WU, Y. Paracrine factors of mesenchymal stem cells recruit macrophages and endothelial lineage cells and enhance wound healing. PloS one, v.3, p.1886, 2008b. https://doi.org/10.1371/journal.pone.0001886

CHERAGHI, M.; NAMDARI, M.; NEGAHDARI, B.; EATEMADI, A. Recent advances in cardiac regeneration: Stem cell, biomaterial and growth factors. Biomedicine \& Pharmacotherapy, v.87, p.37-45, 2017. https://doi.org/10.1016/j.biopha.2016.12.071. 
CROVACE, A.; LACITIGNOLA, L.; ROSSI, G.; FRANCIOSO, E. Histological and immunohistochemical evaluation of autologous cultured bone marrow mesenchymal stem cells and bone marrow mononucleated cells in collagenase-induced tendinitis of equine superficial digital flexor tendon. Veterinary Medicine International, v.2010, p.1-10, 2010. https://doi.org/10.4061/2010/250978.

DAHL, M.; NIKLAS, R.J.; METTE, H.; ELSE, M.P. Carriers in mesenchymal stem cell osteoblast mineralization-state-of-the-art. Journal of Cranio-Maxillofacial Surgery, v.42, p.41-47, 2014. https://doi.org/10.1016/j.jcms.2013.01.047.

DOMINICI, M.; LE BLANC, K.; MUELLER, I.; SLAPER-CORTENBACH, I.; MARINI, F.; KRAUSE, D.; DEANS, R.; KEATING, A.; PROCKOP, D.J.; HORWITZ, E. Minimal criteria for defining multipotent mesenchymal stromal cells. The International Society for Cellular Therapy position statement. Cytotherapy, v.8, p.315-317, 2006.

ESLAMINEJAD, M. B.; ROUHIB, L.; ARABNAJAFI, M.; BAHARVANDA, H. Rat marrow-derived mesenchymal stem cells developed in a medium supplemented with the autologous versus bovine serum. Cell Biology International, v.33, p.607-616, 2009. doi: https://doi.org/10.1016/i.cellbi.2009.03.001.

FAN, Z.; KONG, X.; XIA, J.; WU, X.; LI, H.; XU, H.; FANG, M.; XU, Y. The arginine methyltransferase PRMT5 regulates CIITA-dependent MHC II transcription. Biochimica et Biophysica Acta (BBA) Gene Regulatory Mechanisms, v. 1859, n. 5, p. 687-696, 2016. https://doi.org/10.1016/j.bbagrm.2016.03.004.

FERRIS, R. A; FRISBIE, D. D.; MCCUE, P. M. Use of mesenchymal stem cells or autologous conditioned serum to modulate the inflammatory response to spermatozoa in mares. Theriogenology, v.82, p.36-42, 2014. https://doi.org/10.1016/i.theriogenology.2014.02.015.

FORTIER, L. A.; SMITH, R KW. Regenerative medicine for tendinous and ligamentous injuries of sport horses. Veterinary Clinics of North America: Equine Practice, v. 24, n. 1, p. 191-201, 2008. https://doi.org/10.1016/i.cveq.2007.11.002.

KANG, E.; KIM, D.S.; SUHITO, I.R.; CHOO, S.S. KIM, S.J.; SONG, I.; KIM, T.H. Guiding osteogenesis of mesenchymal stem cells using carbon-based nanomaterials. Nano Convergence, v.4, p.1-14, 2017. https://doi.org/10.1186/s40580-017-0096-z.

KRISTON-PÁL, É.; CZIBULA, Á.; GYURIS, Z.; BALKA, G.; SEREGI, A.; SÜKÖSD, F.; SÜTH, M.; KISS-TÓTH, E.; HARACSKA, L.; UHER, F.; MONOSTORI, É. Characterization and therapeutic application of canine adipose mesenchymal stem cells to treat elbow osteoarthritis. Canadian Journal of Veterinary Research, v.81, p. 73-78, 2017.

RATAJCZAK, J.; WYSOCZYNSKI, M.; HAYEK, F.; JANOWSKA-WIECZOREK, A.; RATAJCZAK, M. Z. Membrane-derived microvesicles: important and underappreciated mediators of cell-to-cell communication. Leukemia, v. 20, n. 9, p. 1487-1495, 2006. https://doi.org/10.1038/sj.leu.2404296

LIM, C.Y.; HAN, J.I.; KIM, S.G.; LEE, C.M.; PARK, H.M. Evaluation of autologous bone marrowderived mesenchymal stem cells on renal regeneration after experimentally induced acute kidney 
injury in dogs. American Journal of Veterinary Research, v.77, p.208-217, 2016. https://doi.org/10.2460/ajvr.77.2.208.

LIU, G.; ZHANG, Y.; LIU, B.; SUN, J.; LI, W.; CUI, L. Bone regeneration in a canine cranial model using allogeneic adipose derived stem cells and coral scaffold. Biomaterials, v.34, p. 2655-2664, 2013. https://doi.org/10.1016/i.biomaterials.2013.01.004.

LUESMA, M.J.; CANTARERO, I.; RANERA, B.; REMACHA, A.R.; CASTIELLA, T.; ROMERO, A.; MARTíN, I.; RODELLAR, C.; JUNQUERA, C. Primary Cilia in Chondrogenic Differentiation of Equine Bone Marrow Mesenchymal Stem Cells: Ultrastructural Study. Journal of Equine Veterinary Science, v.47, p.47-54, 2016. doi: hhttps://doi.org/10.1016/j.jevs.2016.08.002.

MOREAU, J.L.; XU, H.H.K. Mesenchymal stem cell proliferation and differentiation on an injectable calcium phosphate-chitosan composite scaffold. Biomaterials, v.30, p.2675-2682, 2009. https://doi.org/10.1016/i.biomaterials.2009.01.022.

OLIVARES-NAVARRETE, R.; HYZY, S.L.; HUTTON, D.L.; ERDMAN, C.P.; WIELAND, M.; BOYAN, B.D.; SCHWARTZ, Z. Direct and indirect effects of microstructured titanium substrates on the induction of mesenchymal stem cell differentiation towards the osteoblast lineage. Biomaterials, v.31, p.2728-2735, 2010. https://doi.org/10.1016/i.biomaterials.2009.12.029.

PATTERSON-KANE, J.C.; RICH, T. Achilles tendon injuries in elite athletes: lessons in pathophysiology from their equine counterparts. ILAR Journal, v.55, p.86-99, 2014. https://doi.org/10.1093/ilar/ilu004.

RAGETLY, G.R.; GRIFFON, D.J.; LEE, H.B.; FREDERICKS, L.P.; GORDON-EVANS, W.; CHUNG, Y.S. Effect of chitosan scaffold microstructure on mesenchymal stem cell chondrogenesis. Acta Biomaterialia, v.6, p.1430-1436, 2010. https://doi.org/10.1016/i.actbio.2009.10.040.

SHARMA, N.; JEONG, D.K. Stem cell research: a novel boulevard towards improved bovine mastitis management. International Journal of Biological Sciences, v.9, p.818-829, 2013. https://doi.org/10.7150/ijbs.6901.

SILVA, G.V.; LITOVSKY, S.; ASSAD, J.A.; SOUSA, A.L.; MARTIN, B.J.; VELA, D.; COULTER, S.C.; LIN, J.; OBER, J.; VAUGHN, W.K.; BRANCO, R.V.; OLIVEIRA, E.M.; HE, R.; GENG, Y.J.; WILLERSON, J.T.; PERIN, E.C. Mesenchymal stem cells differentiate into an endothelial phenotype, enhance vascular density, and improve heart function in a canine chronic ischemia model. Circulation, v.111, p.150156, 2005. https://doi.org/10.1161/01.CIR.0000151812.86142.45

SMITH, R.K.W.; KORDA, M.; BLUNN, G.W. GOODSHIP, A.E. Isolation and implantation of autologous equine mesenchymal stem cells from bone marrow into the superficial digital flexor tendon as a potential novel treatment. Equine Veterinary Journal, v.35, p.99-102, 2010. https://doi.org/10.2746/042516403775467388.

SUNDIN, M.; RINGDÉN, O.; SUNDBERG, B.; NAVA, S.; GÖTHERSTRÖM, C.; LE BLANC, K. No alloantibodies against mesenchymal stromal cells, but presence of anti-fetal calf serum antibodies, after transplantation in allogeneic hematopoietic stem cell recipients. Haematologica, v.92, p.1208-1215, 2007. https://doi.org/10.3324/haematol.11446 
TAYLOR, S.E.; SMITH, R.K.W.; CLEGG, P.D. Mesenchymal stem cell therapy in equine musculoskeletal disease: scientific fact or clinical fiction? Equine veterinary journal, v.39, p.172180, 2007. doi: 10.2746 / $042516407 X 180868$.

UCCELLI, A.; MORETTA, L.; PISTOIA, V. Immunoregulatory function of mesenchymal stem cells. European journal of immunology, v.36, p.2566-2573, 2006. https://doi.org/10.1002/eji.200636416

WINNING, L.; ROBINSON, L.; BOYD, A.R.; EL KARIM, I.A.; LUNDY, F.T.; MEENAN, B.J. Osteoblastic differentiation of periodontal ligament stem cells on non-stoichiometric calcium phosphate and titanium surfaces. Journal of Biomedical Materials Research, v. 20, p.1-40, 2017https://doi.org/10.1002/ibm.a.36044.

YANG, Y.; ZHONG-YANG, S.; BIN, W.; MING-LI, Y.; BO-YA, Z.; HONG-LI, S. Mesenchymal stem cells improve the outcomes of liver recipients via regulating $\mathrm{CD} 4+\mathrm{T}$ helper cytokines in rats. Hepatobiliary \& Pancreatic Diseases International, v.15, p. 257-265, 2016. doi: 10.1016/S1499-3872 (16) 60085-1

ZHAO, J.; ZHANG. Q.; WANG, Y.; LI, Y. Uterine Infusion With Bone Marrow Mesenchymal Stem Cells Improves Endometrium Thickness in a Rat Model of Thin Endometrium. Reproductive Sciences, v.22, p.181-188, 2015. https://doi.org/10.1177/1933719114537715 